\title{
Centros o conjuntos históricos: Dos modelos para la conservación del patrimonio en entidades menores
}

\author{
Ana Fernández Zamora*
}

En Fernandina, una aldea de Sierra Morena fundada en tiempos de Carlos III, una casa ha roto con un paisaje urbano que se había mantenido intacto desde hace siglos. Las dos hileras paralelas que llevaban la vista al infinito cuentan ya con una vivienda edificada en mitad del eje viario. En las Normas Subsidiarias de Arjona hay un listado de edificios protegidos. Uno de ellos, en la plaza de Santa María ha sido derruido $y$ en su lugar se ha construido una edificación que rompe con el entorno. En Alcalá la Real las viviendas tipo bloque van ganando terreno al caserío tradicional y transformando de paso la imagen urbana. La lista de agresiones es muy larga. Diríase que por estas latitudes el hombre moderno está poseído por un espíritu destructivo y al vaivén de extrañas modas, por un mal entendido progreso, se ha propuesto arruinar enclaves. $Y$ esto es lo preocupante porque ¿qué es lo que se destruye? No es sólo un inmueble, un paisaje históricoartístico o una trama urbana. Lo que se está liquidando es la cultura acumulada en un lugar por los que allí han vivido durante siglos.

El acelerado ritmo de degradación de nuestros centros menores impone una reflexión sobre las estrategias de tutela y, más concretamente, sobre la figura a la que la Ley de Patrimonio encomienda esta tarea, la de Conjunto Histórico. Y es que la experiencia práctica demuestra el abismo que media entre el contenido de la definición legal y la realidad del objeto de protección.
Se ha recorrido un largo camino desde la exclusiva valoración del monumento aislado a la del casco histórico, por lo que la incorporación de la figura de Conjunto a la legislación de Patrimonio es relativamente reciente. Sin embargo, ya contamos con margen suficiente como para concluir que la aplicación de esta figura no es eficaz. Se impone, por lo tanto, una ampliación o evolución del concepto y, en consecuencia, de las propias estrategias de protección.

Este artículo es fruto de las reflexiones desarrolladas en torno a un proyecto de "Análisis de Centros Históricos". El objetivo del trabajo ha sido analizar nueve de estos centros históricos y formular las propuestas de incoación como Conjuntos Históricos para la oportuna protección. Los centros propuestos son entidades menores, diferenciándose entre pueblos y aldeas: Arjona, Bedmar, Lopera, Martos, Aldea de los Rios, Fernandina, Isabela, Acebuchar y Quesada. La complejidad de lo estudiado exige la interdisciplinariedad, un objeto en el que confluyen varias disciplinas, por lo que para su realización ha sido necesario el concurso de distintos profesionales: arqueólogos, arquitectos, geógrafos, delineantes, fotógrafos e informáticos.

Gracias a esta diversidad de puntos de vista, se ha obtenido un conocimiento más global sobre el núcleo urbano estudiado, que ha permitido detectar su singularidad, seleccionar las operaciones de protección e interven-

\footnotetext{
* Historiadora del Arte, contratada por la Junta de Andalucia para la realización de Análisis de Centros Históricos.
} 
ción necesarias, mejorar la futura ordenación, y definir, en su caso, el área propuesta para su declaración como Conjunto Histórico.

\section{EL MODELO DE TUTELA ESTABLECIDO POR LA LEY DE PATRIMONIO: LA FIGURA DEL CONJUNTO HISTÓRICO}

Tanto la definición de la Junta de Andalucía como la del Estado basan el mecanismo de protección en la existencia de un conjunto de inmuebles homogéneos y coherentes. Sin embargo, en demasiadas ocasiones la historia no ha deparado tales agrupaciones. Además en la letra de la ley sólo aparece, como veremos más abajo, una alusión a las "agrupaciones de construcciones", sin que se reflejen modos y calidad de vida, relaciones humanas o entornos físicos, cuando todo ello también conforma la ciudad, tanto o más que los monumentos o las casas. El concepto de ciudad que destilan estas leyes es, pues, incompleto. (BENAVIDES SOLís, 1994, pág. 28)

Asímismo las dos normas establecen el criterio de "clara delimitación", una propuesta de línea rígida y mecanicista que teniendo en cuenta el origen y evolución de nuestros cascos urbanos, es cuanto menos difícil de trazar.

La definición de la Ley del Patrimonio del Estado de 1985 (artículo 14.3) es la que sigue:

"Conjunto histório es la agrupación de bienes inmuebles que forman una unidad de asentamiento continua o dispersa, condicionada por una estructura física representativa de la evolución de una comunidad humana, por ser testigo de su cultura o constituir un valor de uso y disfrute para la colectividad. Asímismo es Conjunto Histórico cualquier núcleo individualizado de inmuebles comprendidos en una unidad superior de población que reúna esas mismas características y pueda ser claramente delimitado".

Tampoco el artículo 27.2 de la Ley del Patrimonio Histórico de Andalucía resuelve los problemas:
"Son Conjuntos Históricos las agrupaciones homogéneas de construcciones urbanas o rurales que sobresalgan por su interés histórico, arqueológico, artístico, científico, social o técnico con coherencia suficiente para constituir unidades suceptibles de clara delimitación".

El criterio de cascos urbanos homogéneos cuadra a la perfeción con núcleos preestablecidos y prácticamente intactos, como los de las colonizaciones de Sierra Morena. Pero la mayor parte de las entidades menores han tenido otro origen y otra evolución, por lo que presentan diferentes áreas según las épocas, bien visibles tanto en la trama urbana como en el escenario arquitectónico.

Salvando las distancias, nos encontramos con un problema similar al planteado hasta hace unos años, cuando las leyes de protección estaban atravesadas por un espíritu de monumentalidad que sólo consideraba merecedoras de salvaguarda a las grandes construcciones. Aquél concepto evolucionó hacia el de los conjuntos históricos para preservar cascos urbanos característicos; ahora constatamos que es necesario ir más allá de su materialidad, porque estos cascos son el producto de la evolución histórica, de las formas de vida y hasta del pensamiento de los vecinos que los habitan.

El interés por el entorno que rodea al monumento surgió a principios de nuestro siglo. Encontramos una muestra en las ideas del arquitecto Gustavo Giovannoni (18731947). Entre ellas, algunas tan revolucionarias como su defensa del asentamiento en el que se encontraban los monumentos. Giovannoni enunció el concepto de ambiente y reivindicó el importante papel de la perspectiva y la definición urbana visual.

La ruptura con los conceptos monumentales fue certificada por la Carta de Venecia de 1964. En ella se resaltaba que el monumento es inseparable del cuadro donde está situado y de la historia de la que es testigo. Las conclusiones de esta Carta se asentaron en los diferentes coloquios de ICOMOS. 
La carta del Restauro del 1972 supuso un salto de gigante al proponer que fuera la estructura urbana el principal eje de valoración, restando importancia al monumento aislado. Además, esta carta es el primer documento que contiene unas instrucciones específicas para la tutela de los centros históricos. Puso de manifiesto el valor de estos asentamientos y no solo por ser testimonios de la civilizaciones del pasado, sino también como documentos de la cultura urbana. La carta del Restauro considera Centro Histórico tanto a los asentamientos humanos con estructuras "unitarias" o "fragmentarias", incluso aunque a lo largo del tiempo se hayan transformado. Las instrucciones recogen gran variedad de aspectos. Junto a los elementos arquitectónicos y urbanísticos considera necesario conservar los elementos naturales que caracterizan de forma más o menos acentuada el conjunto. Así, "Por lo que respecta a los elementos individuales a través de los cuales se efectúa la salvarguarda del conjunto, hay que considerar tanto los elementos edilicios como los demás elementos que constituyen los espacios exteriores (calles, plazas, etc.), e interiores (patios, jardines, espacios libres, etc.) y otras estructuras significativas (murallas, puertas, fortalezas, etc.), así como eventuales elementos naturales que acompañan el conjunto caracterizándolo de forma más o menos acentuada (entornos naturales, cursos fluviales, singularidades geomorfológicas, etc.)".

Las instrucciones y la definición de 1972 fueron completadas en 1975, año declarado por el Consejo de Europa el Año Europeo del Patrimonio Arquitectónico. En la Carta publicada por el Comité de Ministros se deja claro que la protección del patrimonio debe encuadrarse dentro de la política de planeamiento urbano y territorial. Este entendimiento de la protección del patrimonio dentro del marco de la evolución, transformación y crecimiento del casco urbano, introduce un nuevo factor, la sociedad. Por ello se programa la revitalización de los monumentos para darles usos sociales.

La Carta del Restauro de 1987 propuso la sustitución del término "monumento" por el de "Manufactura Histórica". Con esta especta- cular denominación querían sus autores destacar la importancia documental y el aspecto visual de la arquitectura. Una concepción que corona, al menos por el momento, la evolución de la que venimos hablando.

La transformación de este concepto tiene en España un primer reflejo en el Decreto-ley de 1926, en el que por primera vez la legislación traspasaba la idea de monumento individualizado, al referirse a "conjuntos" y "sitios": "Forman parte del Tesoro Artístico Nacional los monumentos o parte de los mismos (...) y las edificaciones o conjuntos de ellas, sitios y lugares de reconocida y peculiar belleza, cuya protección y conservación sea necesaria para mantener el aspecto típico, artístico y pintoresco característico de España ..." Se subraya también la protección al ambiente, al entorno y al carácter: "...la defensa del carácter típico tradicional del pueblo y ciudades que por su importancia lo merezcan". (LÓPEZ JAÉN, J. 1990, pág 60)

La Ley de 1933 denomina al Conjunto de edificaciones "Conjunto Histórico-Artistico". En su artículo 3 establece "...cuidará de la inclusión en el catálogo de monumentos de cuantos edificios lo merezcan, como así mismo de los conjuntos urbanos". En esta referencia a nuestros textos legales, anotamos por último que en la Ley de 1985 el "Conjunto HistóricoArtístico" pasa a llamarse "Conjunto Histórico".

En la década de los años 80 sonaron muchas alarmas. El proceso de crecimiento urbano experimentado en los años inmediatamente anteriores estuvo en demasiadas ocasiones fuera de control. Aún cuando fuera ya tarde para reparar muchos de los desaguisados cometidos, se aprobaron varias disposiciones legales para favorecer la recuperación integrada de los Centros Históricos, con programas de rehabilitación de viviendas. Afortunadamente, estas políticas tuvieron en cuenta consideraciones sociales, económicas y funcionales. Esta recuperación de los centros históricos se consagra en el Decreto-Ley 12/1980 de 26 de septiembre. A través de este texto, se abría en nuestro Ordenamiento jurídico la posiblidad de extender la protección pública a la vivienda por vía de rehabilita- 
ción en lugar de las tradicionales actuaciones que apoyaban las nuevas construcciones.

Como desarrollo del mencionado Decreto se dictó el Real Decreto 2555/I982, de 24 de septiembre, sobre rehabilitación del Patrimonio Arquitectónico en centros urbanos, núcleos rurales y conjuntos histórico-artísticos; norma que, posteriormente, fue sustituida por el Real Decreto 2339/1983, de 28 de julio, sobre Protección a la Rehabilitación del Patrimonio Residencial y Urbano Integrada. (BASSOLS COMA, M. 1990. pág. 479-480)

Recogemos la idea antes apuntada. Es necesario profundizar en la protección del patrimonio y para ello, nada mejor que dotarse de los instrumentos adecuados. $Y$ las leyes solo lo serán si dejan de considerar que nuestros pueblos son agrupaciones de casas. La efectiva protección de nuestros centros menores debe tener en cuenta otros muchos aspectos, para que no suceda como hasta ahora: cuando llega el momento de aplicar los textos legales vigentes, se multiplican los problemas.

\section{METODOLOGÍA. LA DELIMITACIÓN DEL ÁMBITO DEL CONJUNTO}

Repasaremos en primer lugar el método de trabajo seguido en la redacción de diferentes expedientes de análisis de Centros Históricos. El objetivo que se persigue es obtener una imagen global del núcleo urbano y de sus problemas. De esta forma se pueden establecer directrices de protección e intervención, proponer mejoras para la futura ordenación y definir en su caso la propuesta de delimitación.

Para lograr estos objetivos hay que realizar un control cruzado de los distintos aspectos del centro. Son los múltiples factores que configuran un núcleo urbano: la tipología de las viviendas, el parcelarios, los aspectos visuales, su crecimiento a lo largo de la historia, la morfología urbana o su sistema viario. En teoría, al tener en cuenta todos estos elementos se puede delimitar un ámbito "homogéneo" que es el que se propone para su declaración como Conjunto.
No hay que redactar muchos expedientes para darse cuenta de que no siempre todo es tan matemático en la realidad.

El primer problema lo representan las frecuentes lagunas en la información disponible sobre muchos de los campos a tratar. La falta de datos pone en peligro el presupuesto de globalidad que se le supone al proyecto. La mayoría de los centros menores cuentan con escasos estudios singulares, salvando la voluntariosa labor de eruditos locales.

Un problema similar plantea la cartografía. En uno de los casos que citábamos al comienzo -Acebuchar- ni siquiera existe un plano en los organismos oficiales, incluido el Catastro.

Al margen de los problemas prácticos, la metodología de trabajo está marcada por el pliego de prescripciones técnicas,los contenidos de la Legislación, la embergadura del trabajo y la recopilación de información.

En líneas generales los análisis y aspectos recogidos en el proyecto son:

- Análisis Histórico: Este apartado se centra en el conocimiento de la estratigrafía de la ciudad, de las mutaciones y evolución del casco urbano. La finalidad principal es la valoración de las distintas etapas. Este análisis de las transformaciones del casco urbano se realiza a través tanto de las fuentes escritas como de la lectura de la estructura urbana y arquitectónica actual del casco, de las noticias y restos arqueológicos. Los edificios, manzanas y parcelas, captan etapas homogéneas de ocupación del solar urbano. Y, por otro lado, los acontecimientos políticos, económicos, culturales, que se suceden en cada lugar modifican su fisonomía y lo dotan de una forma peculiar. Y junto a esto, completa el estudio otro tipo de documentación como cartografía, dibujos antiguos o fotografías.

Este análisis evolutivo de las distintas fases de la ciudad nos permite averiguar las relaciones de lo antiguo con las remodelaciones y cambios actuales. El análisis centrado en la reflexión pasado/futuro abre el 
camino para considerar las distintas actuaciones individuales actuales.

- El Espacio Público: La existencia de dos tipos de espacios, público y privado, distinguen el mundo urbano del rural, por lo que su análisis permite distinguir las características principales de un casco urbano.

En este primer bloque se estudia los espacios colectivos, de propiedad pública, principales elementos generadores y organizadores del tejido urbano. Se diferencian y estudian la tipología de los espacios públicos, la estructura viaria, su origen, uso, forma y su utilización, ect. Un análisis que está directamente relacionado con otros estudios como el de la percepción urbana pues, los espacios públicos son los canales que focalizan y articulan las imágenes y perspectivas urbanas. Así como, el estudio de la red viaria da la clave para conocer la relación del núcleo urbano con el territorio que lo rodea.

- El Espacio Privado: En este apartado se analiza la forma de privatización del espacio público, los espacios parcelados, que corresponde a lo construido en el casco. Se divide en dos apartados: análisis de la estructura del parcelario y análisis de la tipología edificatoría.

- En el estudio de la estructura del parcelario, el casco urbano aparece como el resultado de las distintas divisiones del terreno con la finalidad de su privatización. Se marcan los límites de cada una de las parcelas, se miden y se diferencian en un plano. El resultado es un mosaico de las diferentes maneras de ocupar y utilizar la parcela. Temas puntuales como las distintas actividades que se desarrollan en el casco urbano marcan distintas necesidades de parcelas, un espacio discontinuo, compartimentado. El resultado del análisis son grupos homogéneos de parcelas resultado de las distintas formas de ocupar el suelo.

- Análisis de la tipología edificatoria: El estudio de la arquitectura no singular dará como resultado un variado mosaico marcado por la renovación y extensión a lo largo de los siglos. Por lo general se trata de un mosaico en el que los distintos tipos edilicios correspondientes a diferentes épocas históricas, se entremezclan. El estudio debe pormenorizarse en diferentes aspectos, como la edad, las características constructivas, el número de plantas, etc. Cada uno de estos aspectos tendrá su propia representación cartográfica.

- Imagen y paisaje urbano: El principal objetivo es el de potenciar la imagen del casco urbano y sus perspectivas históricamente consolidas. La imagen de conjunto, su silueta y perfil, sus elementos: colores, volúmenes o entorno natural, y esto desde cada una de las perspectivas que ofrece el núcleo. Un apartado que se vincula a otros del expediente pues, como ha señalado el profesor Zoido, "...el conocimiento de los fundamentos naturales o históricos que explican los paisajes mejora las posibilidades de intervenir adecuadamente; su desconocimiento u olvido conduce a una acción paisajística de maquillaje, más que de integración". (ZOIDO NARANJO, F. 1944, p. 5) El objetivo es realizar propuestas de perspectivas a proteger, delimitación de bandas protectoras $y$, en definitiva, mecanismos que permitan mejorar la planificación del casco y la integración de nuevos elementos.

- La morfología: la forma del casco urbano. En este apartado el campo de estudio es la forma de los tejidos con una interpretación de las superposiciones y estratificaciones que son testigos de la historia de la ciudad y sus modificaciones. Al entender esta evolución podremos formular propuestas de áreas homogéneas, continuas o no, con problemas y por tanto con soluciones comunes.

- Análisis del patrimonio inmueble. La ciudad es más que un conjunto de casas, pero también es casas y monumentos individuales. Por eso es imprescindible velar por la salvaguarda de los edificios y elementos singulares más relevantes del casco. Su estudio y clasificación debe facilitar la tutela jurídico-administrativa del patrimonio a través de las distintas modalidades de inscripción.

Para una mayor claridad el análisis se realiza mediante fichas individualizadas de los 
inmuebles, clasificadas por los distintos niveles de protección: declarados, con expediente incoado para su declaración como BIC o los que solo requieren una protección parcial o ambiental. Se adjuntan varios de los modelos de fichas utilizadas en esta catalogación.

- Análisis de la arqueología urbana. En síntesis se trata de una recopilación de las noticias sobre yacimientos o zonas arqueológicas y como son tratadas en la normativa urbanística municipal. EL objetivo es plantear las distintas estratégias de actuación: prospeción, excavación.

- Análisis del planeamiento municipal y la legislación sectorial. Aquí se incluyen las determinaciones del planeamiento vigente para dilucidar su repercusiones en el casco, en concreto en lo que atañe al patrimonio para poder hacer recomendaciones sobre las mismas y mejorar la futura ordenación.

- Propuestas

- Propuesta del ámbito a delimitar: Hay que trazar una línea en el plano. Una línea cerrada que debe englobar lo que se propone que sea declarado Conjunto Histórico teniendo en cuenta los criterios enunciados hasta ahora. Por otro lado una tarea imprescindible pues, como ha señalado Martín Bassols, para la configuración formal de un Conjunto Histórico la primera operación procedimental es la delimitación espacial de su ámbito, tanto para la culminación del expediente como para la declaración como BIC. (BASSOLS, 1990, pág. 489).

- Propuestas para los inmuebles singulares por categorias. Propuesta de clasificación por las distintas modalidades de inscripción para facilitar la tutela jurídica-administrativa del patrimonio.

- Recomendaciones: Este apartado debe incluir propuestas para engarzar la política de bienes culturales con otros documentos planificadores y estratégicos vigentes en la localidad. El expediente debe formular directrices de conservación para el planeamiento municipal y la legislación sectorial. También debe incluir recomendaciones al ámbito del planeamiento protector y grado de urgencia de su redacción.

- Planos: La representación gráfica de la información se divide en los dos grandes bloques en que está compartimentada ésta: planos informativos y planos propositivos.

El bloque de planos informativos abarca desde planos donde se aprecia la situación del núcleo en el territorio, con planos a nivel provincial, E I: 200.000, plano de su emplazamiento a menor escala, E I: 10.000, hasta la representación de los distintos aspectos analizados: evolución histórica, en el que se identifican las distintas areas de ocupación del solar, plano de red viaria y espacios libres, estructura del parcelario, tipología edificatoria, edad de la edificación, número de plantas, áreas morfológicas. También se recogen los planos del planeamiento vigente en el municipio que reflejen determinaciones que afecten al patrimonio o con referencias a algún tipo de delitación o medidas para el centro histórico.

También se representan gráficamente los aspectos visuales y la imagen urbana, así como las imágenes más características del casco que generalmente coinciden con los caminos y carreteras principales de acceso. En todas ellas, para facilitar el análisis, se deben resaltar los principales hitos y los elementos impactantes.

En el bloque de planos propositivos se grafían tanto las propuestas como las recomendaciones que han sido previamente formuladas en la memoria. Con este fin se elaboran tres planos: plano de propuesta de delimitación del Conjunto Histórico, plano de Bienes de Interés Cultural (diferenciándose por categorias) y plano de propuesta del ámbito que debe abarcar el planeamiento protector que se juzgue adecuado.

Para sustentar la crítica hacia el concepto legal de conjunto histórico, conviene que comprobemos los resultados de la aplicación de la metodología descrita a varios casos concretos. De nuestra experiencia profesional en Jaén hemos seleccionado los expedientes de decla- 
ración de tres conjuntos que representan tres situaciones bien diferentes, pero que tienen en común la dificultad de adaptar la norma legal.

\section{ENTIDADES COMPACTAS: ACEBUCHAR Y ALDEA DE LOS RÍOS.}

Estas aldeas forman parte de uno de los proyectos reformadores de mayor embergadura en la Historia de España: la colonización de Sierra Morena. El rey Carlos III y un grupo de ilustrados, a finales del siglo XVIII, proyectaron la colonización de una amplia zona desierta en las estribaciones meridionales de Sierra Morena mediante una sociedad rural modélica basada en núcleos urbanos igualitarios y fundada en el trabajo de la tierra como principal fuente de riqueza.

La novedad del asunto estribaba no sólo en el nuevo modelo social que se proponía para estas localidades o en la nueva organización agraria, sino también en que se dibujaba un urbanismo totalmente diferente del que hasta entonces caracterizaba a los pueblos españoles, herederos de la trama urbana que los musulmanes y cristianos dejaron en la Edad Media. Fue una revolución; se ordenaba un territorio, el de Sierra Morena, de acuerdo a un plan preconcebido, se crearon pueblos y aldeas con trazas urbanísticas importadas de Europa, unas trazas que, todavía hoy, siguen sorprendiendo por su elegancia y equilibrio.

El Acebuchar es una de las aldeas construidas sobre un trazado preestablecido bajo los preceptos clasicistas de simetría y orden. (Figura I) La aldea ha conservado íntegra la traza urbana del siglo XVIII, y el caserío, salvo algunas intervenciones, mantiene la tipología tradicional. Prácticamente intacta desde su fundación, es la mínima expresión de casco urbano basado en dos líneas de casas que se abren en los extremos a manera de embudo que recoge al caminante en una escenografía trasladada al campo de lo urbano. El crecimiento y los cambios, desde el siglo XVIII hasta hoy han sido mínimos. La única intervención degradante en la traza ha sido la demolición de una casa que formaba el ala noreste.
Las construciones son homogéneas, pues las casas se levantaron con una tipología determinada por el Fuero de las Nuevas Poblaciones. Son sencillas, de dos plantas, con los huecos bajo la simetria de uno o dos ejes y en su lateral, un arco escarzano para dar paso al corral. Esta unidad de casa-corral, repetida uniformemente, es la base de la configuración urbana de la aldea. Es fácil proponer una delimitación de conjunto histórico para un núcleo urbano así de homogéneo, coherente y compacto. Basta con trazar una línea que abarque todas las casas. (Sobre las Nuevas Poblaciones las obras de GUTIERREZ JULIAN, E. y otros, 1993; PALACIO ATARD, V., 1989; CAPEL MARGARITO, M.,I970; SAMBRICIO, C., I99।.; TORRES BALBAS, CERVERA, CHUECA, BIGADOR, 1954.)

En Aldea de los Rios el problema es similar. Se trata de otro asentamiento colonial que reproduce una plaza barroca europea. Las dos líneas longitudinales a ambos lados de la vía principal, tienen un ensanchamiento hacia su mitad, albergando una pequeña plaza octogonal. (Figura 2)

En este caso, la aldea creció en los extremos con lo que en el ámbito delimitado, la ley de coherencia obliga a distinguir, en una aldea, la zona original del XVIII y su crecimiento posterior, por el que no ha dejado de ser tal aldea. La línea, sin embargo, podría igualmente haber abarcado todas las construcciones en atención a las reducidas dimensiones de la localidad o a su crecimiento apoyado en las líneas heredadas.

En otro orden de cosas, estos núcleos son un buen ejemplo de la necesidad de que la protección del patrimonio se aborde desde el punto de vista supramunicipal. Tanto Aldea de los Ríos como el Acebuchar, además de tener valor por sí mismos, lo tienen por ser testigos de la diversidad morfológica alcanzada en Sierra Morena con el programa de las Nuevas Poblaciones. $Y$ es que cada una de las formas de los trazados de los núcleos urbanos de las Nuevas Poblaciones está supeditada a un proyecto general, en el que con unos simples recursos se alcanzó una gran variedad formal. Por lo que cada uno de estos centros alcanza su valor con respecto al conjunto de aldeas y poblaciones de la que es un modelo más. 


\section{MARTOS: CRECIMIENTO ESPONTÁNEO, SUPERPOSICIÓN Y DISGREGACIÓN.}

Caso opuesto al anterior es el de Martos porque en su casco urbano los asentamientos se superponen. La ocupación del suelo ha sido espontánea y así, en el plano de la ciudad se diferencian distintos tipos de parcelas que, en disposiciones variadas, forman las manzanas y las áreas morfológicas correspondientes a los distintos periodos de ocupación del solar. (Figura 3)

Un escenario de estas características plantea mayores problemas a la hora de definir un conjunto histórico, especialmente con los criterios de homogeneidad, coherencia y "clara delimitación" que exige la ley. El resultado es una línea artificiosa que define un ámbito dentro de la ciudad pero jacaso lo que queda fuera de la línea no forma parte de la historia de Martos?, ¿no configura su imagen urbana?. El resultado de delimitar este ámbito en la ciudad conduce irremediablemente a una mecanicista línea de separación entre áreas de la ciudad por la edad de la edificación y la evolución histórica.

(Sobre el urbanismo en Martos puede consultarse el Informe Diagnóstico de la Consejería de Obras Públicas publicado en 1991).

\section{ARJONA. UN PAISAJE URBANO MUY SINGULAR}

En Arjona el elemento más singular es su paisaje urbano. Y este no sólo está hecho de construcciones homogeneas, o inmubles singulares con posibilidad de adscripción a alguna figura del ordenamiento jurídico, sino que es el territorio, el espacio físico, el que acentua su singularidad. Arjona está sobre una elevación en plena campiña, al romper con su altura la llanura propicia su visibilidad desde muy lejos. Junto a ésto su paisaje urbano es muentra de la herencia de unas estructuras de las que apenas quedan algunos restos pero que aún marcan su perfil: el alcázar, castillo y murallas. Su propia posición estratégica hizo que fuera poblada desde la más remota antiguedad hasta convertirse en uno de los recintos fortificados más complejos de la peninsula en plena edad media. Aunque hoy a penas quedan vestigios de sus murallas su reconstrucción puede realizarse por la documentación que generó el descubrimiento de unas reliquias en el Alcazar en el año 1628. Gran número de eruditos vinieron a esta localidad con la finalidad de presenciar, narrar y, lo que más nos interesa en este caso, dibujar la excavación de las reliquias. Entre ellos destacan el padre Manuel Tamayo, Bernardino de Villegas y la de Jimena Jurado, este último realizó cinco planos del complejo fortificado. Mediante esta documentación, los hallazgos arqueológicos, el análisis del tejido y escenario urbano actual e incluso el nombre actual de algunas calles, ha sido posible no solo reconstruir su historia urbana sino explicar su paisaje. (ESLAVA GALAN, J., 1965).

La imagen que la ciudad ofrece engloba no solo a las "construcciones homogeneas" del casco sino hasta el último edificio construido en la actualidad. (Figura 4) Las antiguas murallas y sus arrabales facilitan la delimitación del ámbito más antiguo y homogéneo de la ciudad. Pero iqué valor tiene este espacio ante la globalidad de un paisaje tan singular?. Por otro lado, si la figura de conjunto es de tutela, es indiscutible que ante la envergadura de este paisaje urbano ésta no puede dejar de coordinar en la ordenación aspectos como las actividades industriales y productivas, los carteles publicitarios, las carreteras de acceso, los vertederos, etc.

\section{UNA POLÍTICA ALTERNATIVA: EL CONCEPTO DE CENTRO HISTÓRICO}

Dos conclusiones se pueden extraer de estos ejemplos representativos de problemas urbanos en centros menores. La primera es la disparidad entre la ley y el objeto a proteger. Y cuando la definición no tiene en cuenta los múltiples aspectos del objeto a proteger -y ésta es la segunda conclusión- la estrategia de protección sufre una importante merma. 
La definición de Centros Históricos viene a superar esta disparidad. En 1977, en un congreso de la UNESCO celebrado en Quito, se definió esta figura como "todos aquellos asentamientos humanos vivos, fuertemente condicionados por una estructura física proveniente del pasado, reconocibles como representativos de la evolución de un pueblo". Desgraciadamente todavia no se ha dado entrada en los textos legales a estas palabras, que revelan un concepto más amplio de ciudad. Y más avanzada aún es la propuesta en lo relativo a una política integral de protección: "la conservación de los Centros Históricos debe ser una operación destinada a revitalizar no sólo los inmuebles, sino primordialmente la calidad de vida de la sociedad que los habita, aplicando su capacidad creativa y equilibrando su tecnología tradicional con la contemporánea". La revitalización "exige un enfoque de planeamiento que la integre en los planes directores del desarrollo urbano y territorial".

Este concepto tienen muy presentes los valores económicos y sociales -más allá de la mera estimación histórico artística- y reclama la participación de los propios vecinos en la protección de lo que les pertenece:

"Los Centros Históricos, por sí mismos y por el acervo monumental que contienen representan no solamente un incuestionable valor cultural sino también económico y social. Los Centros Históricos no solo son patrimonio cultural de la humanidad sino que pertenecen en forma particular a todos aquellos sectores sociales que los habitan".

Como vemos, bajo estas dos definiciones, Centros y Conjuntos, subyacen dos formas de concebir la ciudad. A pesar de que las leyes se refieran a conjuntos de inmuebles, podemos $-y$ debemos- entender la ciudad como un espacio para la vida. Es lo parcial y lo global, representado por el concepto de centro histórico.

Y es que las parcelas y su agrupación, así como los espacios libres, no hacen sino mostrar una civilización en el tiempo, las formas de relacionarse los seres que la habitaron y habitan, su vida pública ...
Sobre la definición dada por el coloquio de Quito, Juan López Jaén comenta "Así pues, los Centros Históricos no son sólo el objeto exclusivo de especialistas en Restauración de Monumentos, sino interés de la ciudadanía, para mejora de sus condiciones de vida y trabajo, y llegar a convertir el Centro Histórico en centro de progreso y desarrollo". (LÓPEZ JAÉN, J., 1990, pág. 329)

\section{ESTRATEGIAS DE CONSERVACIÓN EN CENTROS HISTÓRICOS MENORES}

La alternativa entre conjuntos y centros no es solo una cuestión académica de concepto desde el momento en el que afecta a la estrategia de tutela: una concepción global de la ciudad obliga a la protección de más aspectos y factores.

La Ley del Patrimonio Histórico Español de 1985 estableció la obligación de redactar un Plan Especial en el ámbito que se declarase Conjunto: "La declaración de un Conjunto Histórico, Sitio Histórico o Zona Arqueológi- ca, como Bien de Interés Cultural determinará la obligación para el municipio o municipios en que se encontraren de redactar un Plan Especial de protección u otro instrumento de planeamiento ..." También la Ley del Suelo, en su artículo I7.3 se refiere a la obligación del municipio de redactar un Plan Especial ante la existencia en su término de un área declarada de interés cultural. (BASSOLS COMA, M. 1990. pág. 491)

Aún cuando estas disposiciones reconozcan de forma expresa la eficacia del instrumento urbanístico en la protección del patrimonio y, además, devuelvan a los municipios su competencia sobre los centros históricos (NAVARRO SEGURA, I., 1988, pág. 55), dejan sin solucionar otras cuestiones: ies realmente necesaria la existencia de un planeamiento especial autónomo? ¿es lógico que estas normas especiales afecten $\mathrm{o}$ incluso contradigan a un plan general?

El conflicto se ha plasmado en la práctica del modo más desfavorable para nuestro patrimonio. Muchos planes generales dejaron sin ordenar los cascos históricos en favor de 
un plan especial que en la mayor parte de las ocasiones no llegó a redactarse $\mathrm{o}$, no se ha ejecutado.

A la vista de estos resultados, la Ley andaluza del patrimonio de 1991, otorga libertad de elección en la figura y especifica todas aquellas que pueden elegirse para ordenar el espacio delimitado:

art. 32 "... la ordenación urbanística de los Conjuntos Históricos, Sitios Históricos, Zonas Arqueológicas o Lugares de Interés Etnológico, tanto como catalogados como declarados de interés cultural, podrá llevarse a cabo mediante los siguientes instrumentos:

a) Planes Especiales de Protección o de Reforma Interior.

b) Planes Generales de Ordenación Urbana.

c) Normas Subsidiarias o Complementarias de Planeamiento de ámbito Municipal.

d) Planes Parciales."

Lo que no puede dudarse es que el planeamiento urbanístico es el principal instrumento para tutelar nuestro patrimonio histórico, tanto a nivel individual como de conjunto. El planeamiento general afecta a nuestros centros tanto por incidir directamente sobre el espacio, como al ordenar de forma indirecta el resto de los suelos, con una gran incidencia en cada uno de los aspectos del centro.

Refiriéndonos a los centros menores, llamamos la atención sobre dos cuestiones. En primer lugar, la validez de declarar lo coherente de un casco pequeño, olvidando el resto. En los centros menores, los conjuntos históricos no pueden formar una zona aparte, separada del resto. Esta diferenciación de una parte antigua y otra moderna, separadas por una línea que se ha dibujado en un plano y que solo se refiere a fechas de edificación, es cuanto menos artificiosa. Además, descompensa el desarrollo de los cascos urbanos porque cierra el progreso en el centro y fomentan periferias en las que abundan desequilibrios.
El segundo problema que se encuentra en centros menores es el de la desproporción entre el planeamiento que se propone y la propia dimensión administrativa de ese núcleo. Actualmente, una aldea no está preparada para gestionar planes especiales. Mientras que en una ciudad delimitar uno o varios ámbitos puede ayudar a la ordenación, esa misma estrategia no es válida en centros menores.

Mediocres y rutinarios. Estos son dos calificativos que se pueden aplicar a los documentos urbanísticos vigentes en muchas localidades de la provincia. Los pueblos son castigados con normas subsidiarias que no tienen en cuenta sus particularidades. En muchos casos los documentos son idénticos y solo se molestan en cambiar el listado de monumentos. Se olvida sistemáticamente el patrimonio arqueológico y no se individualiza el lugar. En estos planes fabricados en serie, la tipología, la altura y la alineación de las viviendas -verdadera alma del paisaje en los cascos urbanosson asuntos minimizados.

En esta misma línea no nos resistimos a citar a González Mata:

"Con carácter general, la mayor parte de los trabajos urbanísticos de la provincia, responden a la necesidad de disponer de un documento administrativo que de legalidad a las tramitaciones de licencias de obras y control edificatorio, dejando en un segundo lugar, y en algunos casos está totalmente ausente, la propuesta urbana propiamente dicha; al menos en mi valoración subjetiva, son más documentos administrativos que de ordenación, su objetivo y fin último es reflejar la ley del suelo; y eso en los casos más favorables dado que no siempre fue posible." (GONZALEZ MATA. 1993. pág. 28)

Hay casos extremos, como el de Acebuchar, que no está afectado por norma urbanística alguna; es más, no existe siquiera plano catastral. En cuanto a planeamiento supramunicipal, tampoco fue recogido en el Plan Especial del Medio Físico de la Provincia de Jaén, pese a que otras aldeas de las Nuevas Poblaciones sí fueron tuteladas. 
A la vista de casos como éste, y de otros que hemos citado en este artículo, parece claro que la única posibilidad que tenemos de preservar nuestro patrimonio de los centros menores es aplicar una estrategia global.

Cada día se hace más urgente superar políticas localistas y sectoriales en la intervención urbana, para desarrollar en su lugar una estrategia de recuperación de estos núcleos basada en la ordenación del territorio. En esta ordenación el desarrollo económico y social debe estar entrelazado con la conservación del patrimonio.

Si la figura de protección de los centros menores tuviera en cuenta a las personas que allí viven, el entorno físico, la economía o las actividades productivas, esta tutela será más efectiva que lo que ha sido hasta ahora. La estrategia de protección del patrimonio de centros históricos menores será más efectiva en cuanto que forme parte de un proyecto más global, en la que junto al patrimonio histórico se proteja y organice el medio ambiente, las actividades industriales y productivas, ... y sobre todo a los seres que la habitan. Sobre todo, porque la conservación de las estructuras físicas está directamente relacionada con el tejido social y económico que lo sustenta. Por tanto, desde la visión global del urbanismo es como se puede llevar a cabo la conservación del patrimonio, como un aspecto más de la organización del casco urbano.

Cualquier otra actuación parcial está condenada al fracaso.

\section{BIBLIOGRAFÍA}

AAV (1988): Arquitectura y urbanismo en las ciudades históricas. UIMP-MOPU.

AAVV (1990): La política de rehabilitación urbana en España. Instituto del Territorio y Urbanismo, MOPU.

AAVV (1990): Rehabilitación de los cascos históricos. Diputación Provincial de Granada.

AAV (1994): Patrimonio y Ciudad. Reflexión sobre Centros Históricos. Colección Cuadernos, IAPH. Córdoba.
BARRERO RODRIGUEZ, C. (1990): La ordenación jurídica del Patrimonio Histórico. Oviedo, Civitas.

BARRERO RODRIGUEZ, C. (1993): "Los Conjuntos Históricos y el planeamiento de protección en la Comunidad Autónoma de Andalucía". Rev. Andaluza de Administración Pública, nº 6.

BASSOLS COMA, M. (1990): "Instrumentos legales de intervención urbanística en los Centros y Conjuntos Históricos". Rev. de Derecho Urbanísticos, nI I 8, págs. I3 a 51.

BENAVIDES SOLIS, J. (1994): "El componente cultural en el origen, la evolución y el contenido de los conjuntos históricos". Boletín Informativo. Publicación Trimestral, año III, núm. 10, págs. 28 a 33. Marzo.

BURDALO, S. (1995): "La ciudad como ámbito sostenible de convivencia. Una utopía posible". Rev. MOPTMA, julioagosto, págs. | 88-209.

CAPEL MARGARITO, M. (1970): La Carolina, capital de las nuevas poblaciones. Instituto de Estudios Giennenses.

CASTILLO RUIZ, J. (1994): "Una aproximación a la definición teorica, material, jurídica y procedimental del entorno". Boletín Informativo. Publicación Trimestral, año III, núm. 10, págs. 34 a 37, marzo.

ESLAVA GALAN, J:: "Las defensas de Arjona". Boletín del Instituto de Estudios Giennenses, n० 125 ;

EKHART H. (1994): "La restructuración urbana ecológica". Rev. Ciudad y Territorio, n I0I-I02, págs. 369 a 387.

GARCIA BELLIDO, J. (1988): "Problemas urbanísticos de la Ley del Patrimonio Histórico español: un reto para el urgente desarrollo legislativo y autonómico." Rev. Ciudad y Territorio, n78, págs 3-22.

GONZÁLEZ MATA, A. (1995): "Panorámica sobre el urbanismo de la provincia". Rev. de la Cámara de Comercio e Industria de Jaén, nI14, págs. 19 a 28.

GONZÁLEZ MATA, A. (1993):"Urbanismo próximo a través de la Comisión Provincial". Rev. de la COCl, n97, págs. 26 a 40

GONZÁLEZ MATA, A. (1992):"Reflexiones al hilo del P.E.C.H. de Jaén". Rev. de la COCl, nº 84, págs. 18 a 27.

GONZÁLEZ, F. (1989): Claves para conocer la ciudad. Madrid, Akal.

GUTIÉRREZ JULIAN, E. y otros (I 993): La Carolina. Evolución del modelo territorial de la colonización. Sevilla, Consejería de Obras Públicas y Transportes.

LÓPEZ JAÉN, J. (1990): "Sobre los conjuntos históricos españoles". Rev. Ciudad y Territorio, n85, pág. 325-334.

MORALES TALERO, S. (1965): Anales de la ciudad de Arjona. Ayuntamiento de Arjona.

NAVARRO SEGURA, Ma. I. (1988): "La validez de una política de defensa de los centros históricos: aspectos legales y de ordenación". Rev. Ciudad y Territorio, n77, págs. 5l-57. 
PALACIO ATARD, V. (1989): Las Nuevas Poblaciones Andaluzas de Carlos III. Los españoles de la llustración. Córdoba, Monte de Piedad y Caja de Ahorros.

SAMBRICIO, C. (|99|): Territorio y ciudad en la España de la llustración. Madrid, Ministerio de Obras Públicas.

SCHOONBRODT, R. (1994): "La ciudad es la organización física de la coexistencia". Rev. Ciudad y Territorio, nI00-I0I, págs. 389 a 395.

TERAN. F. de (1978): Planeamiento urbano en la España contemporanea. Historia de un proceso imposible. Barcelona, Gustavo Gili.

\section{RESUMEN:}

Este artículo es una reflexión sobre la figura de Conjunto Histórico, y en concreto, sobre su aplicación a la tutela de entidades menores de población. Ante la experiencia práctica, la primera conclusión es el abismo que media entre el contenido de la definición legal y la realidad del objeto de protección. Y cuando la definición no tiene en cuenta los múltiples aspectos del objeto a proteger, la estrategia de protección sufre una importante merma. En el artículo se concluye con la necesidad de la ampliación o evolución del concepto $y$, en consecuencia, de las propias estrategias de protección. La única posibilidad que tenemos de preservar el patrimonio de los centros menores es aplicar una estrategia más global.

PALABRAS CLAVE: Conjuntos Históricos, Patrimonio Histórico, Urbanismo, Legislación del Patrimonio Histórico, Gestión del Patrimonio Histórico
TORRES BALBAS, CERVERA, CHUECA, BIGADOR (1954): Resumen histórico del urbanismo en España. Instituto de Estudios de Administración Local.

TROITIÑO VIMESA, M.A. (1992): Cascos Antiguos y Centros Históricos. Problemas, políticas y dinámicas urbanas. MOPTMA.

ZARATE MARTÍN, A. (I99|): El espacio interior de la ciudad. Madrid, Síntesis.

ZOIDO NARANJO, F. ( I994): "La ciudad en el territorio". en Patrimonio y Ciudad. Reflexión sobre Centros Históricos, págs. 12-20.

\section{ABSTRACT:}

This article deals with the figure of Historical Sites paying special attention to the protection of small cities. The first conclusion with our practical experience is the great distance between the contents of the legal definition and the reality of the objet to preserve, the strategy of protection suffers an important wastage. This article concludes that the concept needs and evolution or an extension, so the strategies of protection. A global strategy is the only posibility that we have to preserve the heritage of the small cities. 


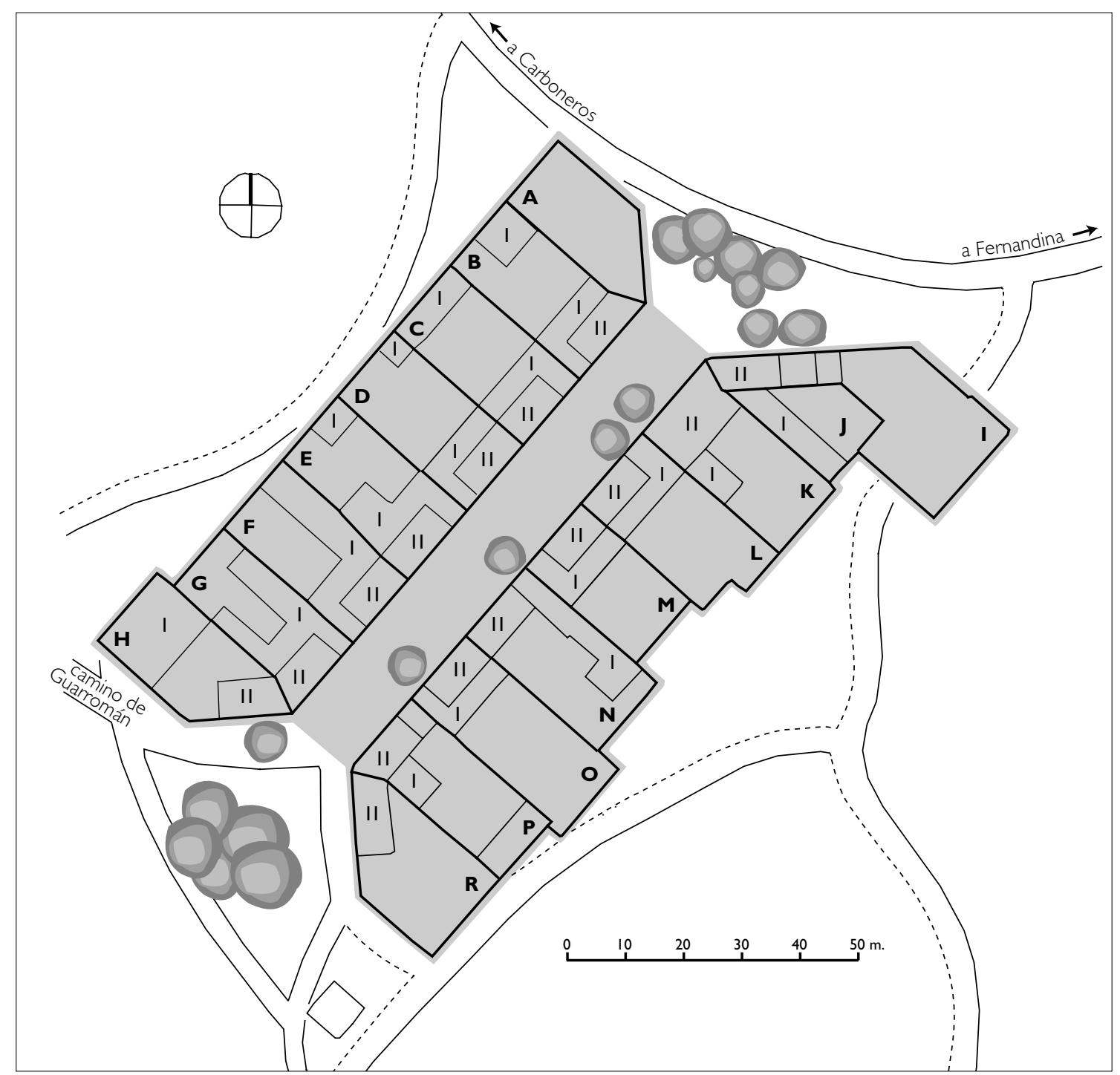

Fig. I. El acebuchar. Plano base realizado por Eduardo Gutiérrez Julián

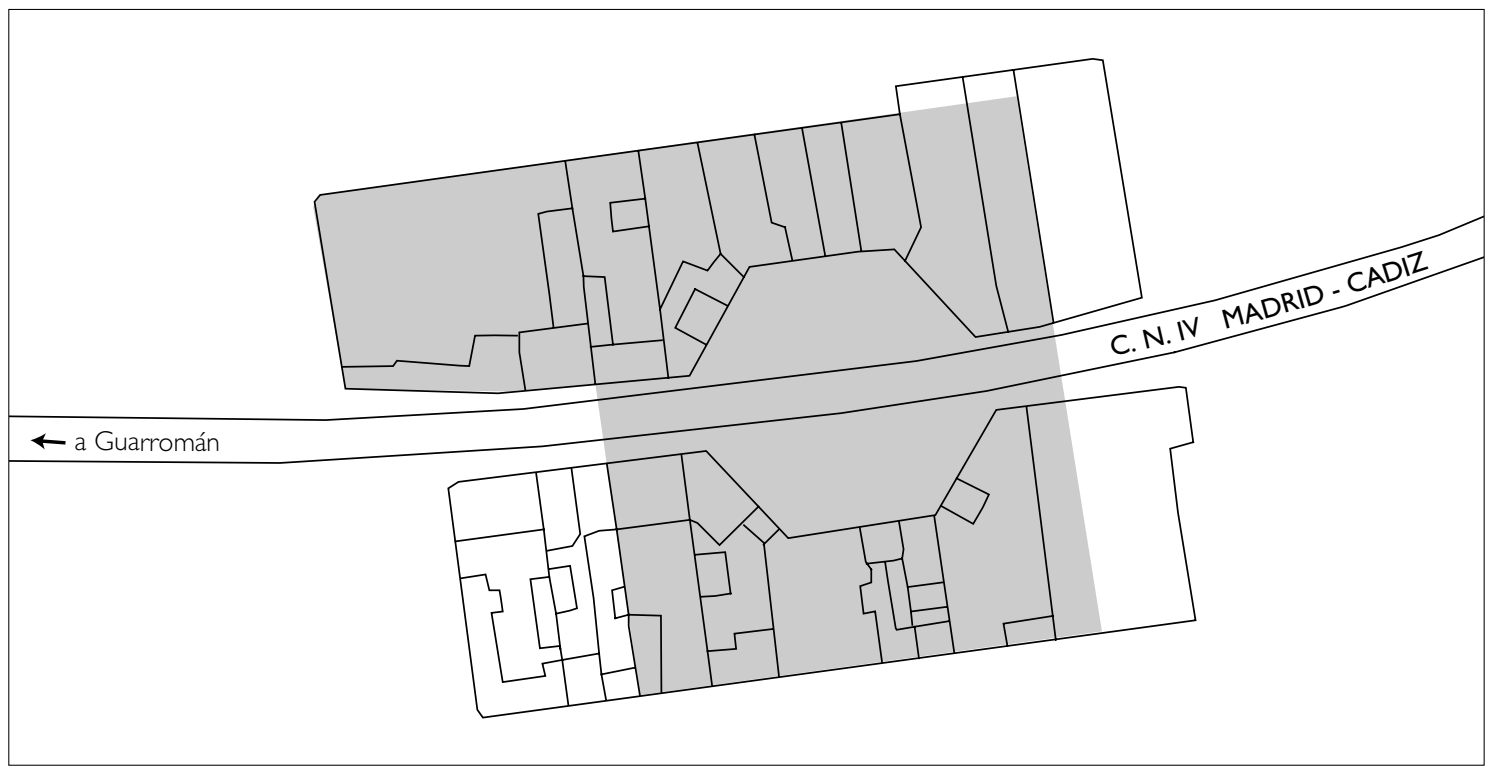

Fig. 2. Aldea de los ríos 


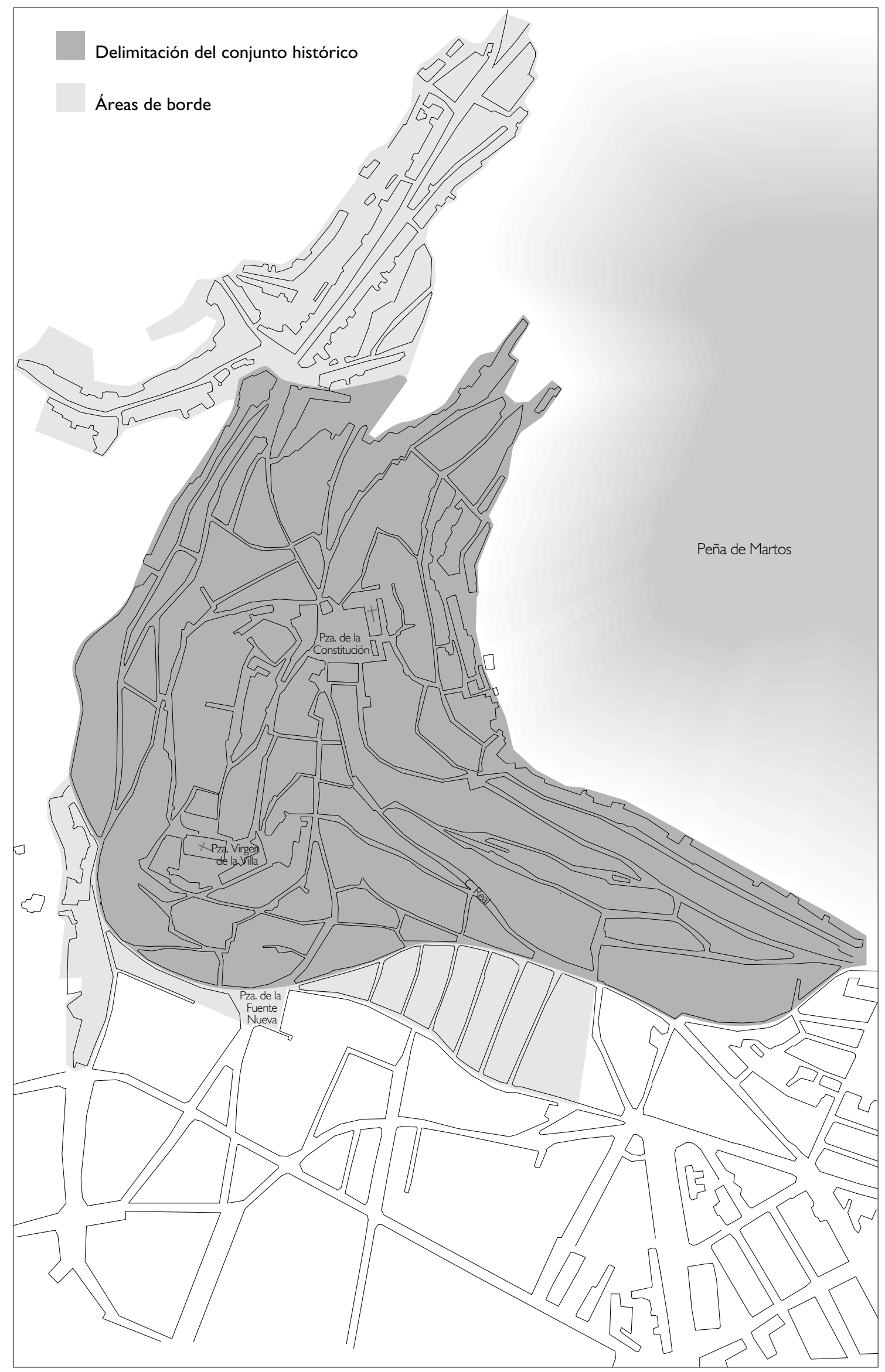

Fig. 3. Martos 


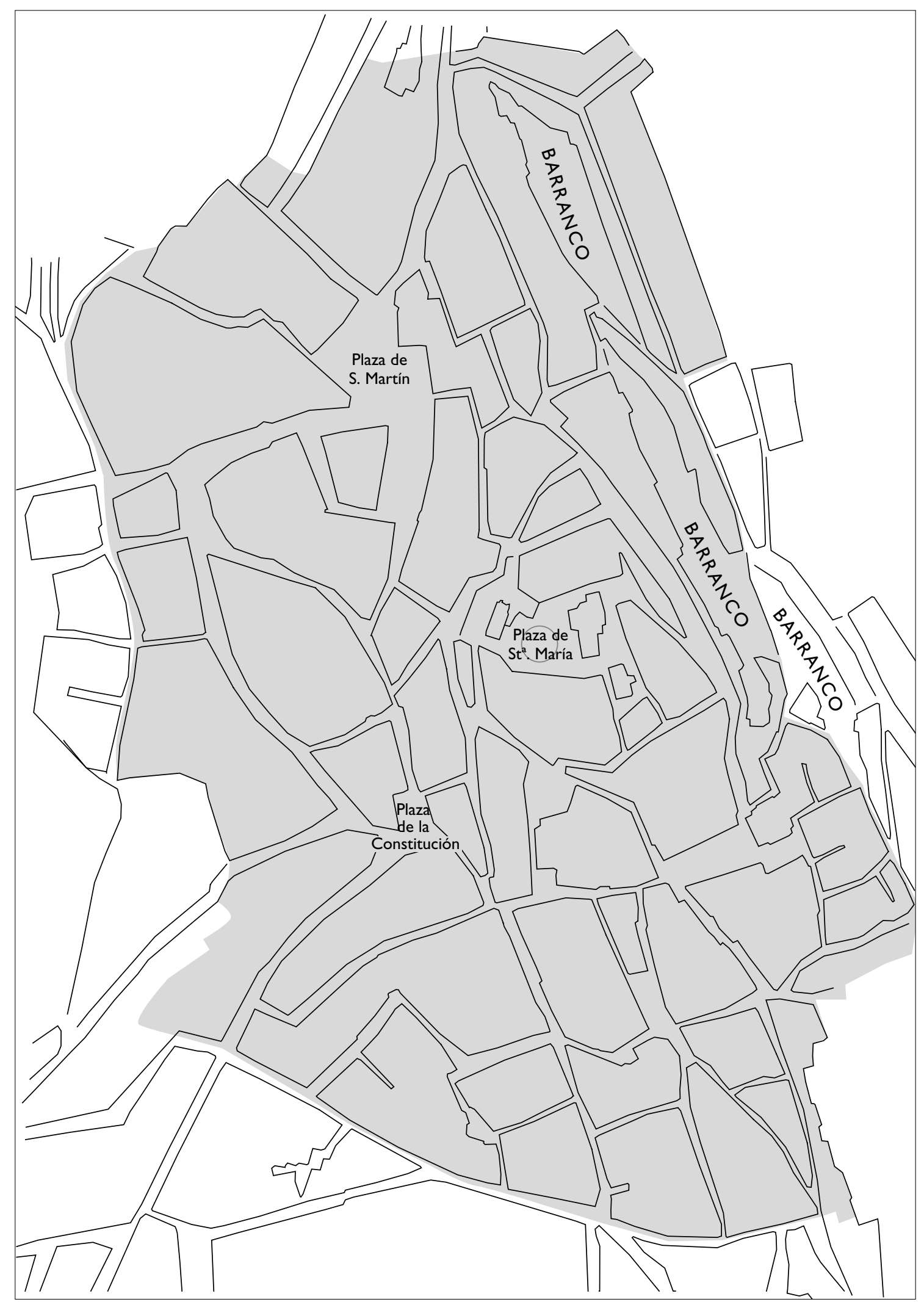

Fig. 4. Arjona 


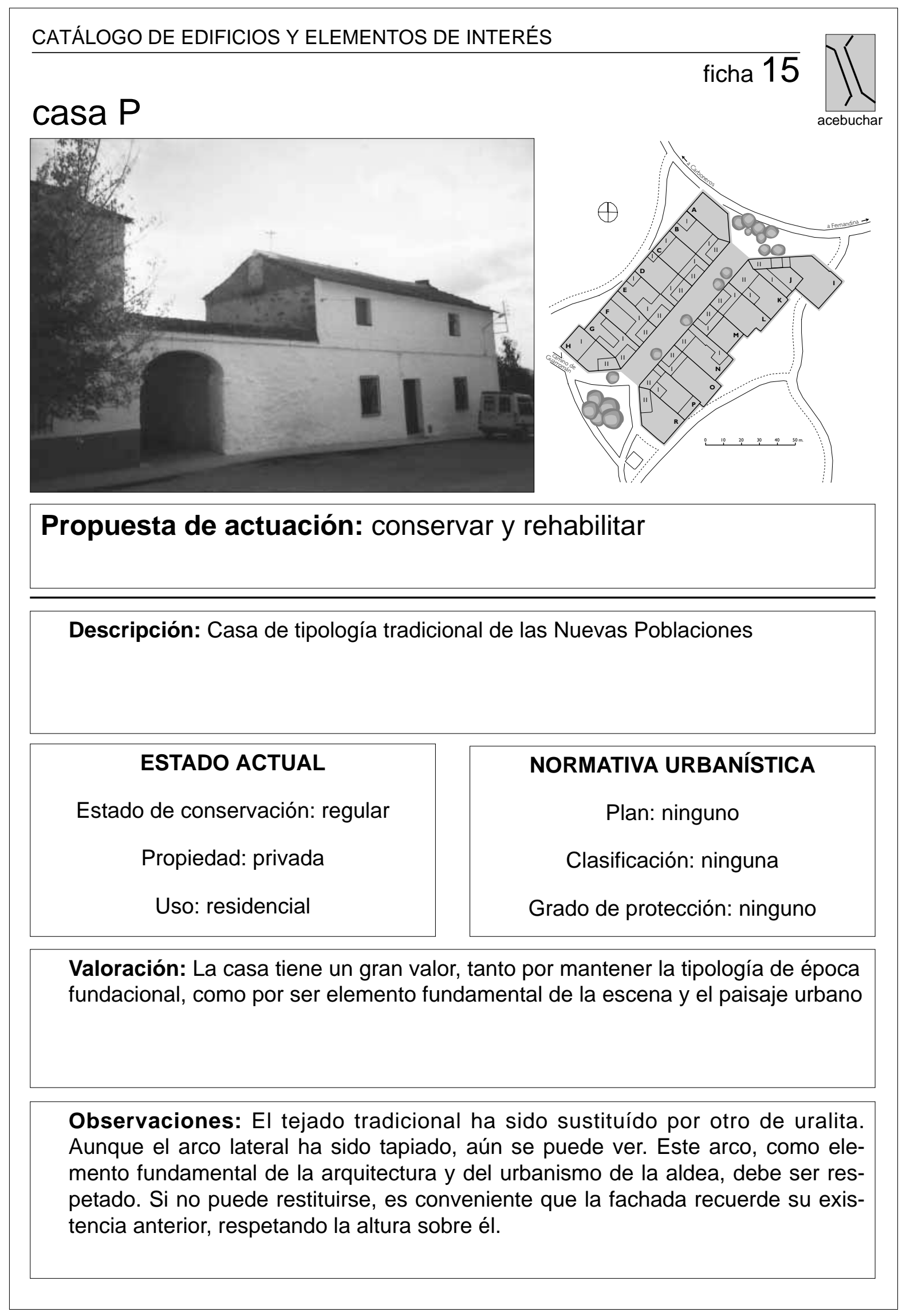




\section{antigua cárcel y Cabildo}

Localización: Plaza de la Constitución, 1

Manzana: 49572

Parcela: 00

Fecha y texto del decreto de declaración: Declarado Monumento Nacional de Interés Histórico-Artístico, en la GAC, con fecha 3-IV-1931. Esta declaración fue ratificada el 8-VI-81, fecha en que fue declarado Monumento Histórico Artístico.

\section{VALORACION DE LA IDONEIDAD DE SU DECLARACION COMO BIC}

Obra maestra de la arquitectura civil de la segunda mitad de siglo XVI, es uno de los edificios más emblemáticos e identificativos de la ciudad de Martos. Ocupa uno de los laterales del principal espacio público de la ciudad desde tiempos anti-

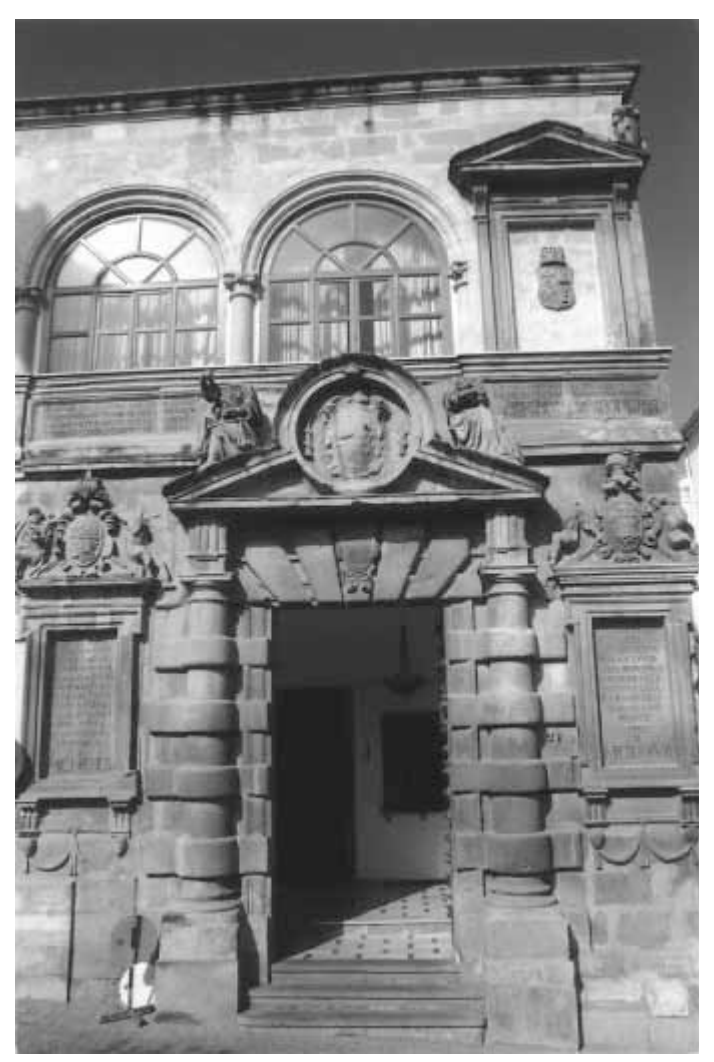
guos: la plaza de la Constitución. En una inscripción de la fachada principai aparece la fecha de finalización de las obras, 1577. El edificio es obra de Francisco del Castillo, por encargo del gobernador don Pedro Aboz Enríquez y de don Antonio de Padilla y Meneses, Justicia mayor del Partido de Calatrava en el Reino de Jaén. ${ }^{46}$

tiene planta cuadrangular, con las dependencias organizadas en torno a un patio central. A éste se accede por un hueco paladiano y el resto de sus muros presenta dos pisos de ventanas pareadas, sobre las que Arsenio Moreno señala que "no son más que un trasunto semiliterales de modelos ofrecidos por Sebastián Serlio en su libro IV". ${ }^{47}$

En la fachada principal consta de dos galerías de arcadas, en el piso inferior con arcos de medio punto y en el superior peraltados sobre columnas de orden corintio $y$ fuste liso.

Del conjunto de la fachada sobresale la portada: puerta adintelada, flanqueada por dos columnas dóricas trabadas y adosadas. El dintel está formado por enormes sillares que en forma radial invaden el entablamento dórico. Sobre éste descansa 
un frontispicio partido por un gran tondo circular que acoge el escudo imperial de los Austrias. En los vértices aparecen recostadas las figuras de la Justicia y la Misericordia. A ambos lados de la portada se sitúan vanos ciegos con mollduras e inscripciones referidas a la construcción del edificio.

El historiador Moreno Mendoza ha descrito los aldabones en bronce de la puerta como" un edículo enmarcado por hermes acabados en garra..", y los ha relacionado con el edículo con estuco y fresco empleado en el palacio romano Máximo delle Colonne entre 1538-1540 48

La fachada lateral derecha, de un severo clasicismo, presenta como decoración un conjunto de lápidas romanas y restos arqueológicos. Sobre el significado de esta decoración aparece una explicación en la Historia de la Antigüedad de Diego de Villalta: "....y todas estas piedras antiguas con letras notables que de presente se han hallado en esta Peña de Martos y pudieron ser traídas, las han mandado ahora juntar y traer de diversas partes y lugares y quitarlas de otros edificios y torres donde estaban puestas y ponerlas todas juntas por maravillosa orden y artificio en el suntuoso edificio público de casas de cabildo y cárcel, que en la plaza de esta villa ha mandado al presente hacer y edificar de nuevo el Ilustre Ayuntamiento y república tucitana de Martos, a cuya diligencia y cuidado deben mucho todos los curiosos de saber estos deleites y provechosos de antigüedades, por haberlas así juntado y puesto en la muralla y pared principal de este edificio, donde con facilidad se pueden leer y sacar las letras y cifras de ellas, por cuya causa será este edificio de los notables y celebrados que haya en España. Donde hallará más de cuarenta piedras antiguas con letras esculpidas y columnas y mármoles de diversos colores, y asimismo estatuas antiguas y otras modernas esculpidas por el singular arquitecto y escultor Francisco del Castillo...". 49

\section{ESTADO ACTUAL DE PROTECCION Y CONSERVACION}

\section{Condiciones de Ordenación}

Régimen del Suelo: Revisión del P.G.O.U.1986

Calificación: Suelo urbano. Casco histórico.

Grado de Protección: Monumento Nacional

\section{Estado Actual}

Uso: Ayuntamiento

Propiedad: Municipal

Estado de Conservación: Este edificio ha sido restaurado recientemente. Una intervención que de la fachada prácticamente sólo ha mantenido la portada y ha cambiado por completo el espacio interior para adaptarlo a tareas administrativas. 


\section{pilar de la fuente nueva}

Localización: Parque "Manuel Carrasco".

Manzana: lindero con la manzana 43491

Parcela:

Fecha y texto de incoación: Tiene incoado expediente de declaración de monumento his- tórico-artístico con fecha 26-6-85, BOJA 70 de 12-8-85 y propuesta de declaración con fecha de diciembre del 87. Tiene redactado el expediente

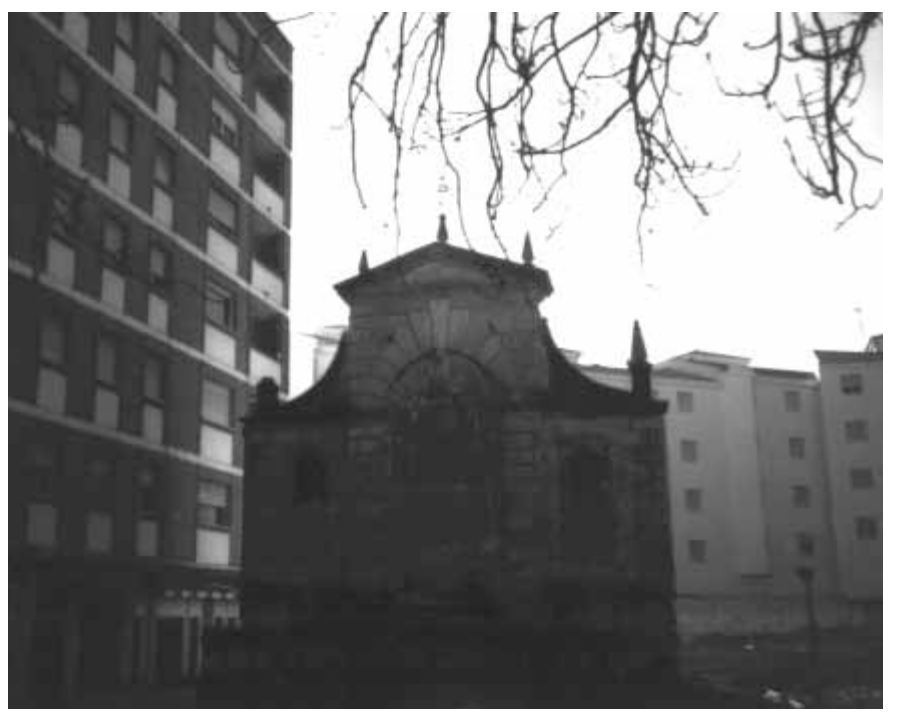
para declaración como Bien de Interés Cultural con fecha de mayo 1989.

\section{VALORACION DE LA IDONEIDAD DE SU DECLARACION COMO BIC}

Obra atribuida al gran arquitecto renacentista Francisco del Castillo, en la cartela puede leerse la fecha de su finalización, 1584.

Está formada por un pilar pequeño y un paramento, de almohadillado rústico, dividido en tres paños, más elevado el central que está unido a los laterales por dos contrafuertes cóncavos, elementos que han sido relacionados con el último Vignola.54 Los dos paños laterales presentan recuadro de almohadillado con decoración de escudos: Calatrava y Martos. El central está formado por un gran arco ciego cuyas dovelas quedan resaltadas en el interior del arco, en el centro presenta un gran águila imperial con el escudo de los Austrias y una cartela, en la parte inferior dos leones a modo de mascarones hacen la función de caños. Está rematado por un frontispicio triangular con pináculos en sus vértices.

Antiguamente estaba situada en la plaza de San Francisco, desde donde fue desmontada y trasladada a varios lugares, hasta su actual ubicación " en un sórdido y lúgubre rincón del parque público Manuel Carrasco".55 Sobre el traslado hay constancia en varios expe- dientes de la Comisión de Patrimonio Histórico sobre el traslado de la Fuente Nueva de Martos, apartado Restauración de Monumentos: Expediente 23/89; 24/ 87; 24/ 88.

Actualmente la Fuente está situada junto a un edificio de siete plantas mas ático, un lugar no sólo no idóneo sino también negativo como entorno de la Fuente. Desde 
aqui aconse jamos el traslado de la Fuente a su primitivo emplazamiento en la plaza de la Fuente Nueva o también llamada de San Francisco. Un traslado que debe realizarse con dos premisas: acondicionar el emplazamiento original, plaza de San Francisco, que haga posible su vuelta y que el proyecto de traslado y conservación se haga con las suficientes garantías de mejorar su situación actual.

\section{ESTADO ACTUAL DE PROTECCION Y CONSERVACION}

Condiciones de Ordenación

Régimen del Suelo: Revisión del P.G.O.U.1986

Calificación: Suelo urbano.

Grado de Protección: Propuesta de declaración, diciembre-1987.

Estado Actual

Propiedad: Municipal

Estado de Conservación: Bueno

Observaciones: Desde 1987 hay redactado un "Anteproyecto de ubicación de Fuente mo- numental con remodelación arquitectónica en la plaza. Martos", que pretendía el traslado de la misma a la plaza de Fuente Nueva.

Hay otra "Propuesta de actuación en la Fuente monumental de Martos", por la Escuela Taller de Rehabilitación del Patrimonio de esta ciudad, redactada en 1994, que propone la puesta en funcionamiento de la fuente. 